\title{
Design of Smart Multi-functional Integrated Aviation Photoelectric Payload
}

\author{
Zhang Xiaoxiao \\ Beijing Institute of Space Mechanics \& Electricity, Engineering Technology Research Center for Aerial Intelligent Remote Sensing
} Equipment of Beijing, Beijing, China - cathy_xiaoxiao@126.com

Commission Urban Sensing and Mobility

KEY WORDS: Photoelectric Technology, Payload, Design, Smart

\begin{abstract}
:
To coordinate with the small UAV at reconnaissance mission, we've developed a smart multi-functional integrated aviation photoelectric payload. The payload weighs only $1 \mathrm{~kg}$, and has a two-axis stabilized platform with visible task payload, infrared task payload, laser pointers and video tracker. The photoelectric payload could complete the reconnaissance tasks above the target area (including visible and infrared). Because of its light weight, small size, full-featured, high integrated, the constraints of the UAV platform carrying the payload will be reduced a lot, which helps the payload suit for more extensive using occasions. So all users of this type of smart multi-functional integrated aviation photoelectric payload will do better works on completion of the ground to better pinpoint targets, artillery calibration, assessment of observe strike damage, customs officials and other tasks.
\end{abstract}

\section{INTRODUCTION}

To coordinate with the small UAV at reconnaissance mission, we've developed a smart multi-functional integrated aviation photoelectric payload. The payload weighs only $1 \mathrm{~kg}$, and has a two-axis stabilized platform with visible task payload, infrared task payload, laser pointers and video tracker.

The photoelectric payload performs well on the capability of all-weather, all-time reconnaissance, the ability to identify camouflage, the capability of moving target indicator, rapid information processing capability and strong viability. Its main mode contains video shooting modes and video tracking mode. The two-axis stabilized platform could isolate the impact of aircraft attitude transformation to the visual axis so as to obtain the clear and stable target image. In addition, the photoelectric payload also has the functions of digital guide, scanning and vertical servo.

\section{RESEARCH STATUS AND APPLICATION PROSPECT}

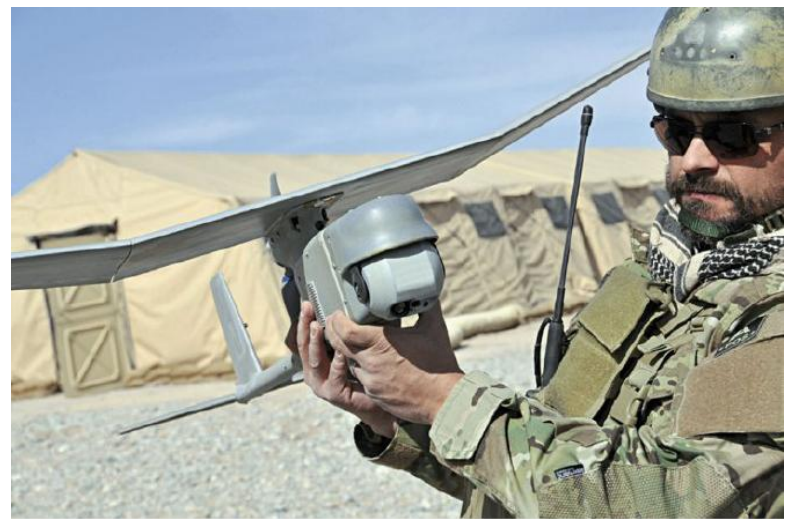

Fig. 1. Appearance of Raven RQ-11

American RQ - 11 "the raven" photoelectric payload on the unmanned aerial vehicle (uav) including visible light camera, infrared thermal imager and a laser designator, together they carry on the two axis stabilized platform, the platform can implement $\mathrm{n} \times 360^{\circ}$ rotating bearing axis, its appearance is shown in figure 1 . The uav reconnaissance system successfully applied in the U.S. war in Iraq and Afghanistan, the user covers the U.S. special operations command, air force, army, navy, and Denmark, Italy, the Netherlands, Spain's army.

With the rapid development of remote sensing technology, whether in the military field, such as battlefield reconnaissance, missile early warning and monitoring of surveying and mapping, or in the civil field, such as resource census, land planning, crop pests and yield investigation, environment pollution monitoring, high resolution, strong comprehensive processing capacity of the development of large-scale remote sensor has made many great achievement. Because aspects of remote sensor performance indicator and the height of the pursuit, as well as the components of the constraints, and the limitation of processing and production technology, to ensure the strict requirements of other aspects, the light sensor design often cannot reach maximum. However, parties to the user for light weight, small volume of multifunctional integration task load demand is becoming more and more strong.

Flexible, strong survival ability of this type of load, can be done quickly and flexibly and various applications, such as the instant of the battlefield reconnaissance missions, rapid objective orientation of public security, the small scale of agriculture precision measurement, pollution index of real-time detection, etc. Now on the market of domestic existing light small remote sensor products, full-featured optical system load more generally in more than $2 \mathrm{~kg}$ weight, is to control the load weight $1 \mathrm{~kg}$ within, often design for single optical system load, when the need for different channel imaging manual hot plug to realize optical switching system. Therefore, the light small multi-function integrated design can satisfy the users and the urgent need of this type sensor led light indicator of developing small photoelectric payload.

\section{THE MAIN RESEARCH WORK AND TECHNOLOGY SOLUTIONS}




\subsection{The user requirement analysis}

3.1.1 Intelligence gathering: As a result of the photoelectric payload light small design, the characteristics of multifunctional integration, can meet the enemy on the battlefield of flexible to collect an important task of military intelligence. Based on the real-time battlefield situation, choose to visible light and infrared imaging, through the unmanned aerial vehicle (uav) platform transmission equipment will be enemy intelligence timely transmission to the ground control subsystem, to provide a strong basis for the establishment of military tasks.

3.1.2 Camouflage recognition: Light small multi-function integrated photoelectric payload of infrared thermal imager can module of target thermal imaging, has certain recognition of disguise, especially can find hidden in people and vehicles in trees and grass, even during the day can discern the military facilities in disguise. The application of infrared technology on military emerged during the second world war, has become one of the important symbol of modernization of military equipment.

3.1.3 Dynamic monitoring: Compared with the military reconnaissance satellites and space remote sensor, light small multi-function integrated photoelectric payload in dynamic monitoring of the field application shows that high flexibility, is of strong maneuverability, targeted prominent advantages. The blow photoelectric payload can according to the real-time demand, choose by soldiers on the battlefield target area and monitor the operation, in actual combat plays a more important role in guiding, raised the rate of a military strike.

3.1.4 Target tracking: Light small multi-function integrated photoelectric payload, to assist the army to enemy targets can be automatic detection, recognition and tracking, to uav target designation, and complete the effective military strike. The load on the video tracker including tracking two work modes of manual and automatic tracking, can achieve the function target recognition and tracking, target display function, target monitoring functions.

\subsection{Working mode research}

Applications and user requirements for the project, on the basis of comprehensive analysis, summarized the photoelectric payload should have all-weather, all-day reconnaissance capability, camouflage ability of recognition, moving target designation, fast information processing ability and a strong ability to survive. Combined with the characteristics of the photoelectric payload, its main working mode contains video shooting mode and video tracking mode. In addition, in order to obtain clear and stable target image, photoelectric payload is equipped with two axis stabilized platform. The platform can isolate the plane visual axis, the effect of posture transformation with digital guide, scanning, vertical servo, etc.

According to the above analysis, the system working mode is shown in figure 2 .

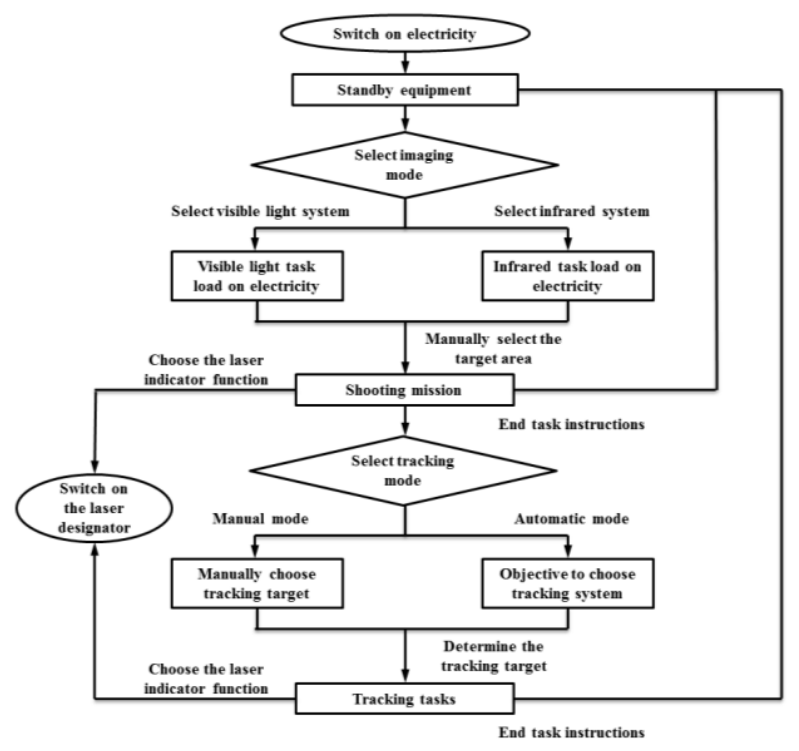

Fig. 2. System working pattern

\subsection{Summary of overall scheme}

3.3.1 System adopts modular design: With the method of modular design, the system can be a huge complex work simplification, each module to achieve a certain function, clear positioning, error processing more efficient. Light small multifunction integrated photoelectric payload is divided into two parts of the machine and the ground, and according to user requirements and work mode analysis, system function module as shown in figure 3 .

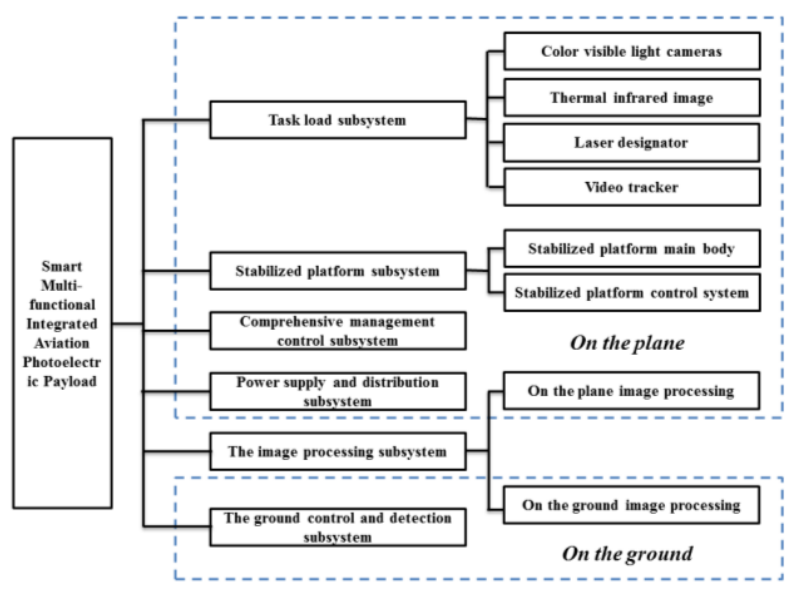

Fig. 3. System function module char

3.3.2 Task load selects the existing mature light small module: In order to ensure the system quality, control, speed up the development process, development costs for the photoelectric load task load subsystem, each component in the selection of existing mature light small module. Among them, the color visible light camera to choose OV5640 module (like RMB $2592 * 2592$ ), the infrared thermal imager is chosen FLIR Tau640 movement (like RMB $640 * 640$ ), a laser designator to choose the infrared point a laser module. 
3.3.3 Multi-function module work together: To each function module and reasonable arrangement, combination, and finally realizes the management coordination, information coordination and resource synergy, complete photoelectric payload internal work, analysis the relationship between the system each function module.

3.3.4 Good impact resistance performance can recover quickly: Considering the light small multi-function integrated optoelectronic load carrying the unmanned aerial vehicle (uav) application environment is complex, especially when landing many uncertain factors, so the photoelectric payload can bear larger impact. Due to the system with the method of modular design, even in the application process a component damage or failure phenomenon, the module can be replaced, achieve the purpose of rapid recovery, real-time application does not affect the battlefield.

\subsection{System composition and functional division}

Light small multi-function integrated photoelectric payload shape as shown in figure 4 , visible light camera, infrared thermal imager, a laser designator and video tracker carry within the spherical shell, and installed on the pitch axis of stabilized platform, the orientation of the stabilized platform shaft connected to the conductive slip ring can achieve $360^{\circ}$ rotation.

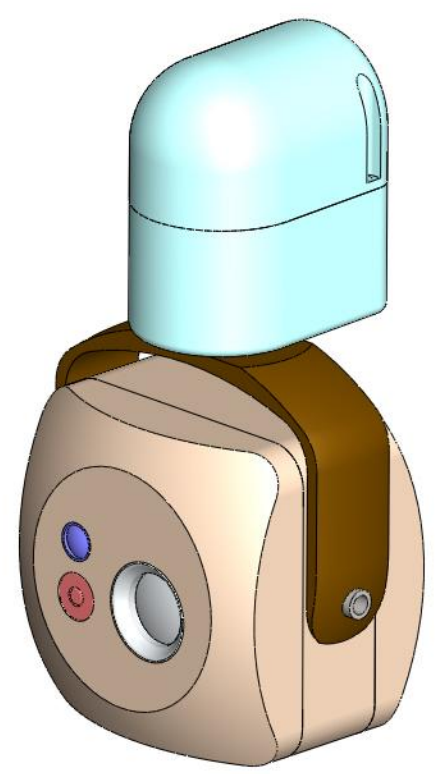

Fig. 4. Appearance of smart multi-functional integrated aviation photoelectric payload

According to the general overview of the overall scheme, the system main function of the parts as shown in table 1 .

\begin{tabular}{|l|l|l|}
\hline \multicolumn{2}{|l|}{ Subsystem } & $\begin{array}{l}\text { Description of main } \\
\text { function }\end{array}$ \\
\hline \multirow{3}{*}{$\begin{array}{l}\text { Task load } \\
\text { subsystem }\end{array}$} & $\begin{array}{l}\text { Color visible } \\
\text { light cameras }\end{array}$ & $\begin{array}{l}\text { To realize visible light } \\
\text { imaging reconnaissance } \\
\text { mission }\end{array}$ \\
\cline { 2 - 3 } & $\begin{array}{l}\text { Thermal } \\
\text { infrared imager }\end{array}$ & $\begin{array}{l}\text { To realize infrared } \\
\text { imaging reconnaissance } \\
\text { mission }\end{array}$ \\
\cline { 2 - 3 } & Laser designator & $\begin{array}{l}\text { For laser reconnaissance } \\
\text { target instructions }\end{array}$ \\
\hline
\end{tabular}

\begin{tabular}{|c|c|c|}
\hline & Video tracker & $\begin{array}{l}\text { On reconnaissance target } \\
\text { recognition, tracking and } \\
\text { monitoring }\end{array}$ \\
\hline \multirow[t]{2}{*}{$\begin{array}{l}\text { Stabilized } \\
\text { platform } \\
\text { subsystem }\end{array}$} & $\begin{array}{l}\text { Stabilized } \\
\text { platform main } \\
\text { body }\end{array}$ & $\begin{array}{l}\text { Platform main bearing } \\
\text { parts, for the task load, } \\
\text { control circuit } \\
\text { components provide } \\
\text { installation and support }\end{array}$ \\
\hline & $\begin{array}{l}\text { Stabilized } \\
\text { platform control } \\
\text { system }\end{array}$ & $\begin{array}{l}\text { Send the command } \\
\text { control platform for } \\
\text { action accordingly }\end{array}$ \\
\hline $\begin{array}{l}\text { Comprehensive } \\
\text { management } \\
\text { control } \\
\text { subsystem }\end{array}$ & & $\begin{array}{l}\text { Receive instruction and } \\
\text { state feedback, } \\
\text { communication and task } \\
\text { load, set the work mode }\end{array}$ \\
\hline $\begin{array}{l}\text { Power supply } \\
\text { and distribution } \\
\text { subsystem }\end{array}$ & & $\begin{array}{l}\text { Used in all parts of } \\
\text { sequence control, power } \\
\text { management }\end{array}$ \\
\hline \multirow[t]{2}{*}{$\begin{array}{l}\text { The image } \\
\text { processing } \\
\text { subsystem }\end{array}$} & $\begin{array}{l}\text { On the plane } \\
\text { image } \\
\text { processing }\end{array}$ & $\begin{array}{l}\text { The task load images } \\
\text { taken for compression, } \\
\text { through the data } \\
\text { transmission module is } \\
\text { sent to the ground }\end{array}$ \\
\hline & $\begin{array}{l}\text { On the ground } \\
\text { image } \\
\text { processing }\end{array}$ & $\begin{array}{l}\text { Through the digital } \\
\text { module receiver sending } \\
\text { image, and to extract }\end{array}$ \\
\hline $\begin{array}{lr}\text { The ground } \\
\text { control and } \\
\text { detection } \\
\text { subsystem }\end{array}$ & & $\begin{array}{l}\text { The setting and } \\
\text { monitoring the status of } \\
\text { the system }\end{array}$ \\
\hline
\end{tabular}

Table 1. System composition and functional description

\section{KEY TECHNOLOGY AND SOLUTION}

\subsection{Light small design system as a whole}

In the light in the process of development of photoelectric payload of small multi-function integration system as a whole on the weight and volume of strict requirements, has brought many constraints. To do to minimize the overall weight and volume, from the selection, structure lightweight design, function module equipped with various electronic components was carried out by a large number of attempts. As far as possible in terms of function module selection, choose the light weight small small integration module, light small design on weight control for whole set aside a certain margin. In terms of structure lightweight design, as the detector, electronic components, etc have been takes up half the weight of the index, therefore, on the premise of guarantee the use requirement, choose low density nonmetallic material structure and processing.

\subsection{Multi-function module integrated together}

Light small multi-function integrated photoelectric payload is integrating a variety of functions, cooperative goal task of general load, in order to reasonable arrangement, combination, and each function modules and eventually work together, to the function of each subsystem to achieve a comprehensive decomposition, sorted out and working mode based on workflow. To write the programs written for control of workflow into the integrated management of control circuit of FPGA chip, the implementation system of the multi-function module work together, a highly integrated. 


\subsection{Light small stabilized platform control technology}

To isolate unmanned aerial vehicle (uav) platform for photoelectric device, the influence of light small multi-function integrated photoelectric payload is introduced into the design of the two axis stabilized platform. The platform control system sampling rate gyro sensitive information, constitute the closedloop feedback loop. Through the design of the corresponding correction network, drive motor driven load compensation due to the involvement of torque developed by the carrier attitude change, achieve optical payload attitude stability. On the other hand, a stable platform control system based on photoelectric encoder as the position feedback component, the command signal and feedback signal error correction, control motor driven load steady rotation, realize the function such as search and tracking.

\subsection{Impact resistance performance and quick rehabilitation design}

Considering the light small multi-function integrated photoelectric payload using battlefield in the need of real-time surveillance aspect, fully considering the impact resistance performance of the system, under the certain external impact damage behavior, such as not affect performance, load itself even if the overall system structure, produce the phenomenon such as separation, crushing, also can operate by personnel simple manual reassemble, fast repair, replacement of spare parts and other forms this kind of tenacious survival ability can better adapt to the ever-changing complex battlefield environment.

\section{CONCLUSION}

The total weight of $1 \mathrm{~kg}$, can realize the infrared, visible, and equipped with double optical system imaging laser instructions and video tracking, carrying two axis light small multi-function integrated photoelectric stabilized platform load, because of its small volume weight and set up perfect function, the comprehensive performance of highly integrated design, will assist in real time in the future battlefield reconnaissance uav platform play an important role.

\section{REFERENCES}

Davy, H., Roland, D. A Challenge for Micro and Mini UAV. The Sensor Problem, RTO-MP-SET-092, pp. 13.

ZHOU, J., WANG, Z., 2011. Research on Unmanned Aerial Reconnaissance Vehicle Opto-electronic Load Development. Video application \& project, 35(31), pp. 141 144. 